\title{
Novel weight functions and stress intensity factors for quarter- elliptical cracks in lug attachments
}

\author{
S. Akbari, S.M. Nabavi \\ Faculty of Aerospace Engineering, Malek Ashtar University of Technology, Tehran, Iran \\ Saleb_akbari66@yahoo.com \\ Nabavi@mut.ac.ir, bttp://orcid.org/0000-0002-3803-843X
}

H. Moayeri

Department of Mechanical Engineering, West Tehran Branch, Islamic Azad University, Tehran, Iran. Moayeri.bamed@wtiau.ac.ir

\begin{abstract}
In this paper, a general weight function is developed to calculate the stress intensity factors (SIFs) for quarter-elliptical cracks in a wide range of lug attachment family. For this purpose, a series of finite element analyses are performed. Finally, using this unique extracted weight function, the influence of the pin loading model and crack parameters (aspect ratio and relative depth of the quarter-elliptical crack) on the SIFs is evaluated in the cracked lug attachments. The results of the present work are compared with some data available in the literature, and the agreement is satisfactory.
\end{abstract}

KEYWORDS. Attachment lug; Quarter-elliptical crack; Weight function; Stress intensity factor; 3D finite element analysis

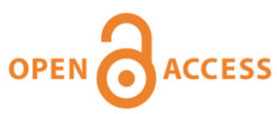

Citation: Akbari, S., Nabavi, S. M., Moayeri, H., Novel weight functions and stress intensity factors for quarter-elliptical cracks in lug attachments, Frattura ed Integrità Strutturale, 47 (2019) 39-53.

Received: 06.09 .2018

Accepted: 20.10.2018

Published: 01.01.2019

Copyright: (C) 2019 This is an open access article under the terms of the CC-BY 4.0, which permits unrestricted use, distribution, and reproduction in any medium, provided the original author and source are credited.

\section{INTRODUCTION}

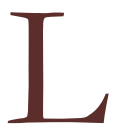

ug-type joints are one of the most useful and serviceable types of attachments in aerospace industries, which play an important role in the integrity of mechanical structures. Because of their application and loading condition, these parts are very critical. The stress distribution around the hole of lugs and the complexity of pin loading makes these parts critical and may result in cracks initiation. To evaluate the crack growth, firstly a fracture study should be done, which leads to fatigue life estimation. For this study, calculation of stress intensity factor (SIF) is very important and should be achieved precisely to ensure the precision of the results of next stages.

It is helpful to perform stress analysis before starting from a fracture study. Jiang et.al[1] performed a 3D numerical analysis using finite element method (FEM) to investigate the effect of geometrical parameters of a lug on its stress concentration factor (SCF). They found that SIF is very sensitive to the change of these parameters. In addition, they reported that SIF has almost a linear relation with the friction coefficient. Wang [2] studied the stress fields in a lug under various loading conditions, such as the contact and clearance between the lug and a pin. It was shown that the effect of rigidity between the 
pin and lug on stress distribution is small. Grant and Flipo [3] made a parametric analysis to study the change of interference between a pin and a lug hole, together with the effect of the radius of the hole and thickness of the lug on the stress. This paper takes into account both 2D and 3D FEM models and their results.

Studying the fracture of a lug due to its loading condition as mentioned earlier is necessary. There are many approaches to obtain SIF in a cracked lug to evaluate its fracture. Kathiresan et al. [4] used a 2D FE fracture analysis on a tapered lug. Results show that in a tapered lug, SIF has a lower value than a straight lug for symmetric loading. A similar work were performed by Hsu [5] on a tapered and a straight lug. The effect of lug and crack parameters on the stress distributions and SIF were determined in both cases. Kathiresan et al. [6] obtained SIF solutions for through cracks in lugs using the Green's function method and correction factors. Narayana et al. [7] analyzed the presence of cracks in metallic and composite lugs using finite element analysis. Boljanović and Maksimović [8] and Boljanović et al. [9] carried out two similar investigations, in which they obtained the SIFs for both through and surface cracks using 3D FEM analysis. Naderi and Iyyer [10] used three type of pin loadings such as full contact problem, cosine pressure distribution and uniform pressure distribution in their XFEM model. Results confirmed that SIFs came from full contact loading of the pin is higher from those two other models. Also, Naderi et al. [11] used an extended isogeometric analysis in order to calculate SIF in lug attachments which uses some new functions. The resulted SIFs were used to study the crack growth of straight attachment lugs. Rigby and Aliabadi [12] used the boundary element method and the J-integral to obtain SIFs in a single quarter elliptical and symmetrical quarter elliptical cracks in a lug. Wang [13] extracted a weight function (WF) for a wide range of through cracks in a lug based on the boundary element method. Mikheevskiy et al. [14] employed the WF technique for fatigue crack growth analysis of a cracked lug using the load-shedding effect. The shape of crack changed from a quarter circular to an edge crack in the crack growth process of that quarter elliptical crack. Wu and Tong [15] provided a 1D WF to calculate the crack surface displacements of cracks in radial. Xu et al. [16] developed an analytical 1D WF for a pin-loaded specimen with a single crack at mixed mode condition. Bahloul et al. [17] considered crack tip residual stress field and material dispersion in their fracture modelling of a lug. The proposed approach was able to predict the fatigue crack growth in lug attachments with a good reliability. There are some similar works like the Newman's papers $[18,19]$ that formulated SIFs in finite plates which contain a hole with cracks. These formulas could not be used for lug parts because of the difference in geometry, boundary condition and also the ratio of hole radius to the width of lug. In a different work, Chikmath and Dattaguru [20] used a prognostic analysis to monitor the criticalities in lug attachments during fatigue crack growth. In this paper, they made it possible to change the contact condition between lug and pin during the fatigue loading.

The goal of present work is to compute a weight function to predict stress intensity factors in a wide range of lug attachments family, which is very useful in their life estimation. The considered flaw configuration is a quarter-elliptical crack which is located inside the lug. Extraction of the WF is based on the 3D FE analyses. The computed WFs can be employed for both surface and deepest points of the quarter-elliptical cracks. The proposed WF could be used for the cracks in lugs having different ratios of width to radius in the lug's hole, as well as different aspect ratios and depth ratios for the crack. Because of these characteristics, the extracted WF is a unique and independent tool, which could be used in many problems with different loading condition, lug geometries, and crack configurations. It means that in the literatures there is no similar WF, which could cover a wide range of lugs and be presented in the paper with its educational aspects. The outcomes of the present WF are compared with special cases in the literature to verify the results of this paper. The results obtained are in good agreement with those available in literature. The derived WF can play an important role to assess fatigue crack growth in attachment lug. Finally, the effects of loading types on the SIFs are studied as an application of present WF.

The characteristics and novelties of the WF presented in this study could be summarized as:

- Capability in calculating SIFs in the lugs containing quarter-elliptical corner cracks subjected to complex stress distributions.

- Feasibility to be used in a board range of lug's family with different geometries having various quarter-elliptical cracks' parameters.

- Proposal of efficient WFs for the estimation of crack growth in lug attachments.

\section{GEOMETRY OF THE ATTACHMENT LUG AND THE MATERIAL PROPERTIES}

7 he examined lug is made of Al 7075 T7351 and shown in Fig.1. $R_{o}$ is the outer radius of the lug, $R_{i}$ is the radius of $\operatorname{lug}$ hole, and $B$ is the thickness of lug. In order to extract a WF valid for a range of lug parameters, values of $R_{o}$ and $R_{i}$ are not constant.

The parameters of the quarter elliptical crack in this lug are $a$ and $\mathrm{c}$ as described in Fig.1. Further, $a$ and $c$ are involved in the WF achievement process, they have variable values which will be presented in the WF later. The cracked lug is made of 
7075 T7351 aluminium alloy. Poisson's ratio and Young's modulus of this material are 0.32 and 71 GPa, respectively. Linear elastic fracture mechanics analyses are employed to determine the SIFs.
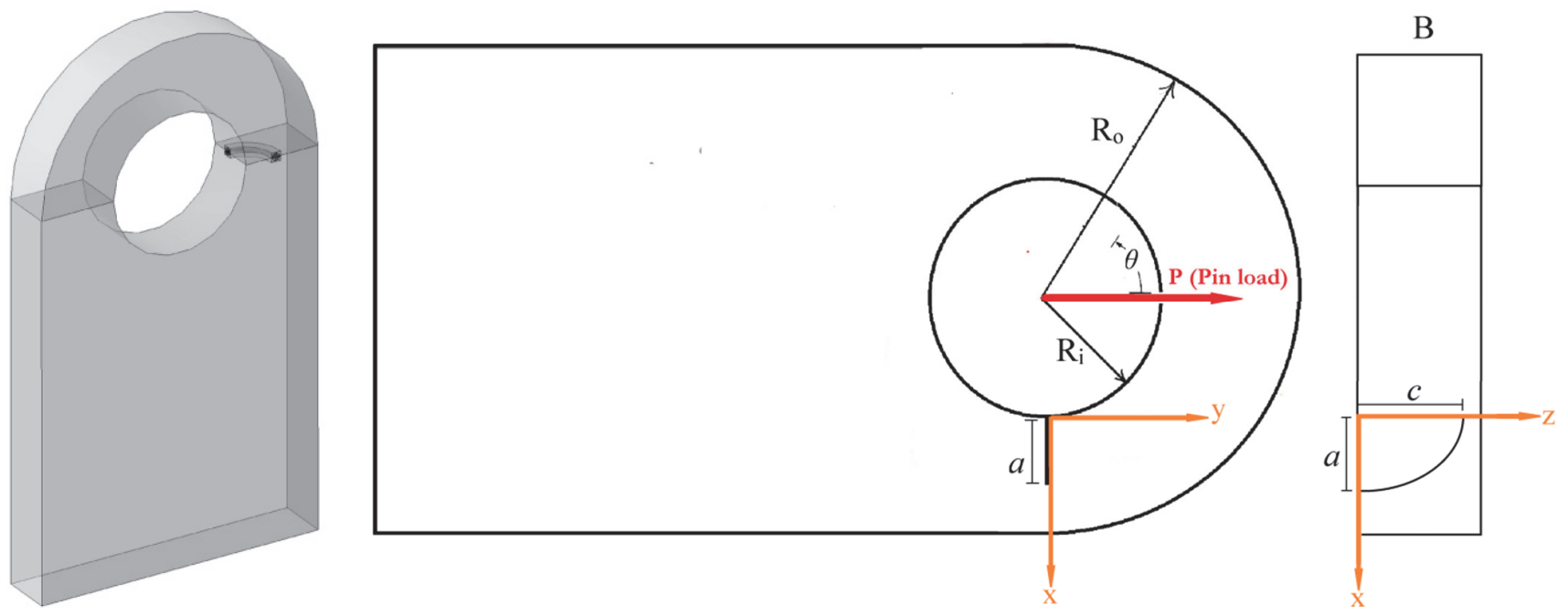

Figure 1: Schematic of a straight attachment lug with a quarter-elliptical crack.

\section{WEIGHT FUNCTION EXTRACTION PROCEDURE}

$\mathrm{I}$ $\mathrm{n}$ this section, all related steps to achieve the WF are presented. During the first step of the process, a numerical analysis (FEA) should be used to determine the SIFs for two reference loads. Considerable attention must be paid when 3D FEA results are sensitive to element size and convergence. At this point, the results of the analysis are employed to obtain the WF. At the end of these steps, further verifications are performed on the computed results.

\section{Finite element analysis}

In order to achieve a WF it is very important to have enough results, at those ranges of parameters that would be the variants of the function. Here, three variables are considered, which are: $\mathrm{R}_{\mathrm{o}} / \mathrm{R}_{\mathrm{i}}, a / c$ and $\mathrm{c} / \mathrm{B}$. Their ranges are defined according to literatures. These ranges are 1.5 to $3,0.2$ to 1 and 0.2 to 0.8 for $\mathrm{R}_{\mathrm{o}} / \mathrm{R}_{\mathrm{i}}, a / \mathrm{c}$ and $\mathrm{c} / \mathrm{B}$, respectively. By considering a constant value of $B$, the other parameters could be calculated according to that. The considered variation of these parameters is presented in Tab. 1 for one family of the cracked lugs.

\begin{tabular}{lc}
\hline \multicolumn{1}{c}{ Parameter } & Value \\
Aspect ratio of quarter-elliptical crack $(a / c)$ & $0.2,0.4,0.6,0.8,1$ \\
Depth ratio of the quarter-elliptical crack $(\mathrm{c} / \mathrm{B})$ & $0.2,0.4,0.6,0.8$ \\
Ratio of outer to inner radius of the lug's hole $\left(\mathrm{R}_{\mathrm{o}} / \mathrm{R}_{\mathrm{i}}\right)$ & $1.5,2.25,3$ \\
Radius of the lug's hole $\left(\mathrm{R}_{\mathrm{i}}\right)$ & $19.05 \mathrm{~mm}$ \\
Thickness of the lug $(\mathrm{B})$ & $12.7 \mathrm{~mm}$ \\
\hline
\end{tabular}

Table 1: Geometrical parameters of the cracked lug.

According to these parameters, 3D finite element models are developed in ABAQUS [21] FE program to obtain SIFs corresponded to each condition. Because of the location and the shape of crack in the lug, same as the schematic in Fig. 1, the complete model is employed. 3D meshes are implemented for these analyses as shown in Fig. 2. 20-node brick elements are used for all parts of the lug, except the region around the crack tip. Collapsed wedge-shaped elements, which midpoints are shifted to quarter points, are implemented for crack tip region due to the singularity. There are three general methods for calculating stress intensity factors from FEA. These methods are: displacement extrapolation (DE), the stiffness derivative technique (SDT), and the J-integral technique. Both the DE method and the SDT are sensitive to mesh accuracy 
around crack front using singular elements. The J-integral method, instead, reduces this problem. J-integral method is chosen in ABAQUS for calculating the SIFs in these analyses.
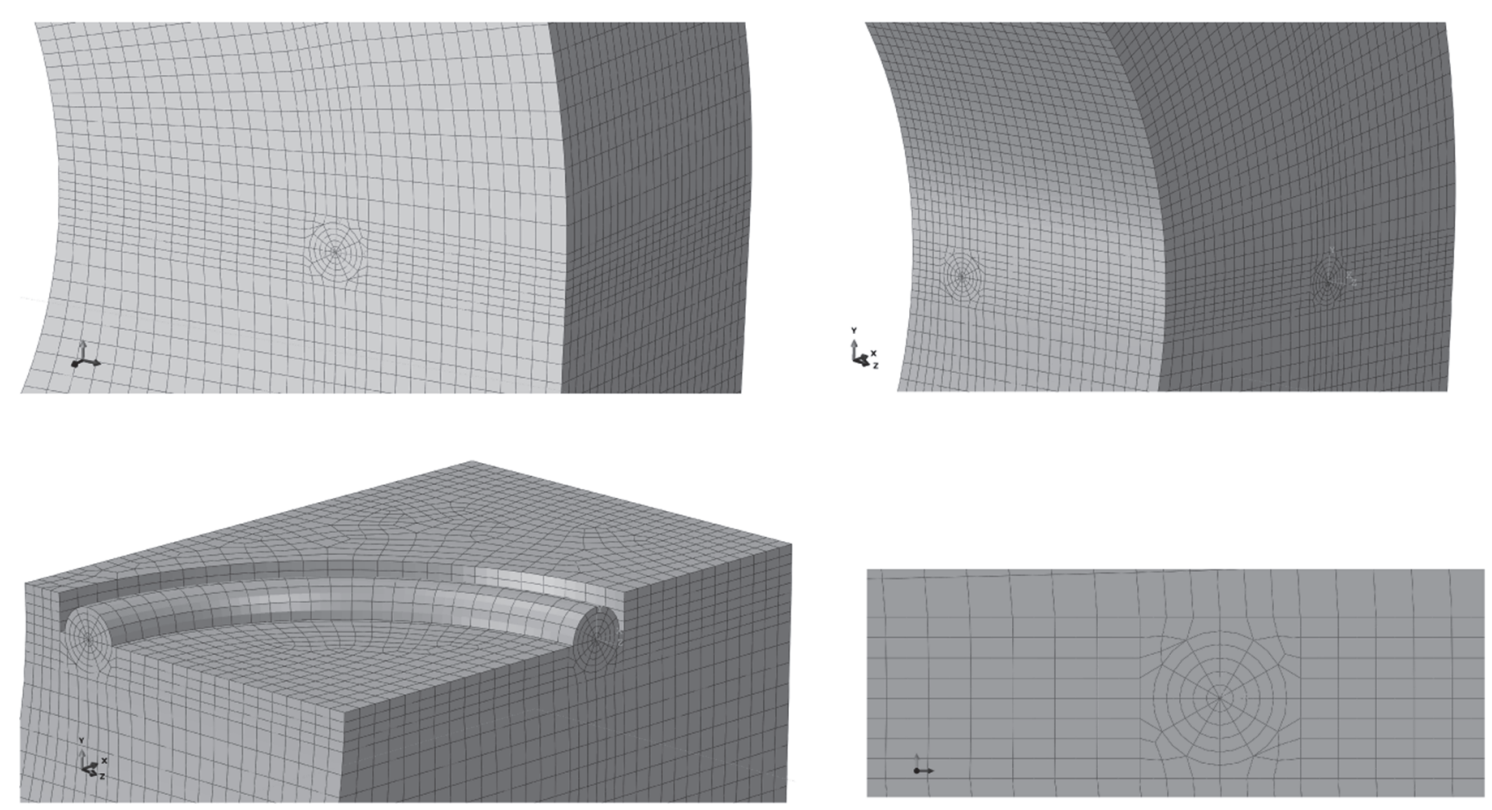

Figure 2: Typical FEM mesh for the complete cracked lug.

The SIFs due to reference loading are calculated for determining the WF. The stress distributions across the plane of the crack specify are regarded as reference loads. The crack face is subjected to a general power-law stress distribution. The general equation to introduce the reference loading is given by:

$$
\sigma(x)=\sigma_{0}(1-x / a)^{n}
$$

where $n$ is a positive integer number and is equal to 0 and 1 for uniform and linear reference loadings, respectively. $x$ is the distance from the inner surface of the hole (moving positive towards), $\sigma_{0}$ is the amplitude of the loading, and $a$ is the crack length according to Fig.1. ABAQUS has this ability to give SIFs directly, but SIFs are achieved from J-integral as follows:

$$
K_{I}=\sqrt{J E /\left(1-v^{2}\right)}
$$

About Eqn. (2) it should be noted that, this equation is valid for the points which have singularity with the power of 0.5 , but for the end points of the crack front the power of singularity is not equal to 0.5 . Therefore, the results will be extracted near these end points on the crack front to have accurate results [22-24]. The results from the uniform and linear reference loadings would be used in the process of fitting curves for extracting the WF.

\section{Verification of FEM results}

Because FEM results are the base part of this work, a separate verification is done. In order to verify the resulted SIFs of this work, Refs. [6, 8] are used (Tab. 2). The lug is subjected to the pin loading. The rigid pin was considered to fit in the lug hole with zero clearance and frictionless. In this case the pin has contact with the hole of lug (both have equal radius) and the applied force is in the y-direction, according to Fig.1. The surface and deepest points of the crack (A and B) are introduced (Fig.3) for this comparison. The results are normalized $\left(K_{N}=K_{I} / \sigma_{\mathrm{br}} \cdot \sqrt{\pi a}\right.$ which $\sigma_{\mathrm{br}}=\mathrm{P} /\left(2 . \mathrm{R}_{\mathrm{i}}\right.$. B) and $P$ is the total pin load in the lug). SIFs here obtained are compatible with those reported in Refs. [6, 8].

It is obvious that the results of the present FE model are compatible with analytical and FE results of mentioned references and the maximum difference is about 4 percent. 


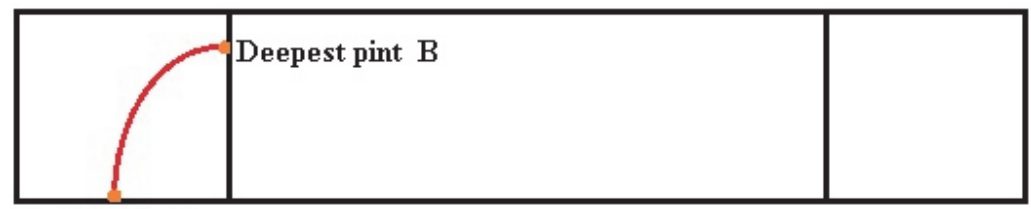

Surface pint A

Figure 3: Surface point (A) and the deepest point (B) on the quarter-elliptical crack in the attachment lug.

\begin{tabular}{cccccc}
\hline $\mathrm{R}_{\mathrm{o}} / \mathrm{R}_{\mathrm{i}}$ & $\mathrm{c} / \mathrm{B}$ & Location & & $\mathrm{K}_{\mathrm{N}}$ & \\
& & & FEM (present work) & Analytical [6] & FEM [8] \\
2.0 & 0.22 & surface & 1.28 & - & 1.32 \\
2.0 & 0.22 & deepest & 1.69 & - & - \\
2.25 & 0.50 & surface & 0.97 & 1.01 & - \\
2.25 & 0.50 & deepest & 1.31 & 1.34 & - \\
2.25 & 0.78 & surface & 1.01 & 0.98 & - \\
2.25 & 0.78 & deepest & 1.36 & 1.41 & \\
\hline
\end{tabular}

Table 2: Comparison of the obtained SIFs for the quarter-circular crack $(a / c=1)$ in a lug under the pin loading.

\section{The weight function extraction}

The basis of the WF method is the SIF calculation process, which is independent of the loading shape. The SIF corresponding to $\sigma(\mathrm{x})$ (see Eqn. (3)) can be determined for arbitrary loading on the considered points on the crack front (here deepest and surface points) by a single integration:

$$
K=\int_{0}^{a} \sigma(x) \cdot m(x, a) d x
$$

where $K$ is the SIF for an arbitrary loading, $\sigma(\mathrm{x})$ is the stress distribution equation on the crack plane for the un-cracked lug and $\mathrm{m}(\mathrm{x}, a)$ is the appropriate WF for this geometry. For a corner crack, this WF would be determined as:

$$
m(x, a)=\frac{H}{K} \frac{\partial u(x, a)}{\partial a}
$$

where $H$ is a constant of material and can be expressed by:

$$
\begin{array}{ll}
H=E & \text { for plain stress } \\
H=E /\left(1-v^{2}\right) & \text { for plain strain }
\end{array}
$$

$u$ is the crack face displacement which has the effects of boundary condition inherently. According to Ref. [26] the general form of WF for corner cracks at the surface and deepest points are given by:

$$
m_{A}(x, a)=\frac{2}{\sqrt{2 \pi(a-x)}}\left[1+M_{1 A}\left(1-\frac{x}{a}\right)^{1 / 2}+M_{2 A}\left(1-\frac{x}{a}\right)+M_{3 A}\left(1-\frac{x}{a}\right)^{3 / 2}\right]
$$




$$
m_{B}(x, a)=\frac{2}{\sqrt{\pi x}}\left[1+M_{1 B}\left(\frac{x}{a}\right)^{1 / 2}+M_{2 B}\left(\frac{x}{a}\right)+M_{3 B}\left(\frac{x}{a}\right)^{3 / 2}\right]
$$

where $M_{i A}$ and $M_{i B}$ (with $i=1,2,3$ ) are constants of the WF for the surface and the deepest point of the crack respectively, and could be calculated using two reference loadings (uniform and linear) and an added condition. The added condition for calculating the constants of the WF for surface point of the crack [27] is that the second derivative of WF should be zero at $x=0$ :

$$
\frac{\partial^{2} m_{A}(x, a)}{\partial x^{2}}=0 \quad \text { at } x=0
$$

The condition for the deepest point of the crack is that the value of the WF at $\mathrm{x}=a$ should be zero.

$$
m_{B}(x, a)=0 \quad \text { at } x=a
$$

The obtained equations from these two conditions are

$$
\begin{aligned}
& M_{2 A}=3 \\
& M_{1 B}+M_{2 B}+M_{3 B}+1=0
\end{aligned}
$$

If Eqns. 10 and 11 are used, only two reference stress intensity factors have to be known. By considering $\sigma(\mathrm{x})$, when $n$ is equal to 0 (uniform stress) and 1 (linear stress), the SIFs are for the surface point of crack:

$$
\begin{aligned}
& K_{\text {uniform-surface }}=\sigma_{0} Y_{0} \sqrt{\pi a / Q} \\
& K_{\text {linear-surface }}=\sigma_{0} Y_{1} \sqrt{\pi a / Q}
\end{aligned}
$$

whereas for the deepest point of the crack are:

$$
\begin{aligned}
& K_{\text {uniform-deepest }}=\sigma_{0} F_{0} \sqrt{\pi a / Q} \\
& K_{\text {linear-deepest }}=\sigma_{0} F_{1} \sqrt{\pi a / Q}
\end{aligned}
$$

where $Y_{0}, Y_{1}, F_{0}$ and $F_{1}$ are correction factors that can be obtained from curve fitting of FEM results (uniform and linear) and are function of $\mathrm{R}_{\mathrm{o}} / \mathrm{R}_{\mathrm{i}}, a / \mathrm{c}$ and $\mathrm{c} / \mathrm{B} . Q$ is the shape parameter for elliptical crack, which is based on a series expansion of an elliptic integral of the second kind and can be approximated as [25]:

$$
Q=1+1.464(a / c)^{1.65} \quad 0 \leq a / c \leq 1
$$

Substituting Eqns. 6 and 12 into Eqn. 3, the WF constants for the surface point of the crack can be found as

$$
\begin{aligned}
& M_{1 A}=\pi / \sqrt{2 Q}\left(4 Y_{0}-6 Y_{1}\right)-6.25 \pi \\
& M_{2 A}=3
\end{aligned}
$$




$$
M_{3 A}=\pi / \sqrt{2 Q}\left(-6 Y_{0}+12 Y_{1}\right)+1.6
$$

In the same way, substituting Eqs. 7 and 13 into Eqn. 3 and using Eqn. 11, the constants $M_{i B}$ for the deepest point of the crack can be determined as

$$
\begin{aligned}
& M_{1 B}=\pi / 2 \sqrt{Q}\left(30 F_{1}-18 F_{0}\right)-8 \\
& M_{2 B}=\pi / 2 \sqrt{Q}\left(60 F_{0}-90 F_{1}\right)+15 \\
& M_{3 B}=-\pi / 2 \sqrt{Q}\left(42 F_{0}-60 F_{1}\right)-8
\end{aligned}
$$

Four equations are obtained by curve fitting on the FEM results under uniform and linear reference loadings in order to achieve $Y_{0}, Y_{1}, F_{0}$ and $F_{1}$. These fitting equations are function of $\mathrm{R}_{\mathrm{o}} / \mathrm{R}_{\mathrm{i}}, a / c$ and $\mathrm{c} / \mathrm{B}$. The concluded WF specifications which are the novel results of this work and given by:

$$
\begin{array}{ll}
Y_{k}=\sum_{i=1}^{3} \sum_{j=1}^{3} \sum_{l=1}^{3} A_{k i j l}\left(\frac{\mathrm{R}_{o}}{\mathrm{R}_{i}}\right)^{i-1}\left(\frac{a}{c}\right)^{j-1}\left(\frac{c}{B}\right)^{l-1} & k=0,1 \\
F_{k}=\sum_{i=1}^{3} \sum_{j=1}^{3} \sum_{l=1}^{3} B_{k i j l}\left(\frac{R_{o}}{R_{i}}\right)^{i-1}\left(\frac{a}{c}\right)^{j-1}\left(\frac{c}{B}\right)^{l-1} & k=0,1
\end{array}
$$

\begin{tabular}{|c|c|c|c|c|c|}
\hline \multirow[t]{2}{*}{$k$} & \multirow[t]{2}{*}{$i$} & \multirow[t]{2}{*}{$j$} & \multicolumn{3}{|c|}{ l } \\
\hline & & & 1 & 2 & 3 \\
\hline \multirow{7}{*}{0} & \multirow{3}{*}{1} & 1 & 0.921 & -0.227 & 0 \\
\hline & & 2 & 0.161 & 1.884 & 0 \\
\hline & & 3 & 0 & 0 & 0 \\
\hline & \multirow{4}{*}{2} & 1 & 0.004 & 0.067 & 0 \\
\hline & & 2 & 0.027 & -1.572 & 0.897 \\
\hline & & 3 & 0 & -0.161 & 0 \\
\hline & & 1 & 0 & 0 & 0 \\
\hline \multirow{11}{*}{1} & \multirow[t]{3}{*}{3} & 2 & 0 & 0.358 & -0.339 \\
\hline & & 3 & 0 & -0.017 & 0.372 \\
\hline & & 1 & 0.250 & -0.055 & 0 \\
\hline & \multirow[t]{2}{*}{1} & 2 & 0.063 & 1.080 & 0 \\
\hline & & 3 & 0 & 0 & 0 \\
\hline & \multirow{4}{*}{2} & 1 & 0.016 & 0.023 & 0 \\
\hline & & 2 & -0.001 & -0.893 & 0.5 \\
\hline & & 3 & 0 & -0.221 & 0 \\
\hline & & 1 & 0 & 0 & 0 \\
\hline & \multirow[t]{2}{*}{3} & 2 & 0 & 0.223 & -0.221 \\
\hline & & 3 & 0 & 0.003 & 0.338 \\
\hline
\end{tabular}

In addition, values of coefficient $A_{k i j l}$ and $B_{k i j l}$ are listed in Tab. 3 and Tab. 4, respectively.

Table 3: Coefficient $A_{\text {kijl }}$ in the boundary correction factor for the reference loads. 


\begin{tabular}{|c|c|c|c|c|c|}
\hline \multirow[t]{2}{*}{$\mathrm{k}$} & \multirow[t]{2}{*}{ i } & \multirow[t]{2}{*}{$\mathrm{j}$} & \multicolumn{3}{|c|}{1} \\
\hline & & & 1 & 2 & 3 \\
\hline \multirow{8}{*}{0} & \multirow{3}{*}{1} & 1 & 0.374 & -0.376 & 0 \\
\hline & & 2 & 0.739 & 2.314 & 0 \\
\hline & & 3 & 0 & 0 & 0 \\
\hline & \multirow{4}{*}{2} & 1 & -0.036 & 0.1395 & 0 \\
\hline & & 2 & 0.075 & -0.594 & 0.077 \\
\hline & & 3 & 0 & -1.685 & 0 \\
\hline & & 1 & 0 & 0 & 0 \\
\hline & \multirow[t]{3}{*}{3} & 2 & 0 & 0.217 & -0.324 \\
\hline \multirow{10}{*}{1} & & 3 & 0 & 0.2104 & 1.199 \\
\hline & & 1 & 0.292 & -0.034 & 0 \\
\hline & \multirow[t]{2}{*}{1} & 2 & 0.662 & 1.444 & 0 \\
\hline & & 3 & 0 & 0 & 0 \\
\hline & \multirow{4}{*}{2} & 1 & -0.044 & 0.072 & 0 \\
\hline & & 2 & 0.097 & -0.784 & -0.144 \\
\hline & & 3 & 0 & -1.043 & 0 \\
\hline & & 1 & 0 & 0 & 0 \\
\hline & \multirow[t]{2}{*}{3} & 2 & 0 & 0.328 & -0.243 \\
\hline & & 3 & 0 & 0.001 & 1.22 \\
\hline
\end{tabular}

Table 4: Coefficient $B_{\text {kijl }}$ in the boundary correction factor for reference loads.

A set of computations have been accomplished to identify the accuracy of the derived WF expressions. The stress distribution is applied as an input to calculate the SIFs using the WF integral in Eqn. 3. The SIFs are computed from WF for the quadratic and cubic stress distribution acting on the crack faces using $n=2$ and 3 in Eqn. 1 respectively. The calculated SIFs were compared with the FEM results, and these comparisons are shown in Tab. 5-7, for $\mathrm{R}_{\mathrm{o}} / \mathrm{R}_{\mathrm{i}}=1.5,2.25$ and 3.0, respectively. The comparison between the computed and FEA results point out that the derived WF can be applied for reliable calculation of the lug with quarter-elliptical crack. The maximum difference does not exceed more than 7 percent.

\begin{tabular}{|c|c|c|c|c|c|c|}
\hline \multirow{3}{*}{$a / c$} & \multirow{3}{*}{$\mathrm{c} / \mathrm{B}$} & \multirow{3}{*}{ Location } & \multicolumn{4}{|c|}{$K_{N}=K_{I} /\left(\sigma_{0} \cdot \sqrt{\pi a / Q}\right)$} \\
\hline & & & \multicolumn{2}{|c|}{ parabolic } & \multicolumn{2}{|c|}{ cubic } \\
\hline & & & WF & FEM & WF & FEM \\
\hline \multirow{8}{*}{0.2} & \multirow{2}{*}{0.2} & surface & 0.203 & 0.210 & 0.142 & 0.150 \\
\hline & & deepest & 0.470 & 0.464 & 0.436 & 0.445 \\
\hline & \multirow{2}{*}{0.4} & surface & 0.197 & 0.202 & 0.137 & 0.144 \\
\hline & & deepest & 0.463 & 0.448 & 0.428 & 0.413 \\
\hline & \multirow{2}{*}{0.6} & surface & 0.195 & 0.201 & 0.137 & 0.143 \\
\hline & & deepest & 0.457 & 0.451 & 0.422 & 0.417 \\
\hline & \multirow{2}{*}{0.8} & surface & 0.202 & 0.212 & 0.142 & 0.150 \\
\hline & & deepest & 0.454 & 0.466 & 0.420 & 0.429 \\
\hline \multirow{8}{*}{1} & \multirow{2}{*}{0.2} & surface & 0.192 & 0.187 & 0.130 & 0.129 \\
\hline & & deepest & 0.868 & 0.839 & 0.766 & 0.750 \\
\hline & \multirow{2}{*}{0.4} & surface & 0.240 & 0.235 & 0.169 & 0.166 \\
\hline & & deepest & 0.879 & 0.846 & 0.789 & 0.756 \\
\hline & \multirow{2}{*}{0.6} & surface & 0.337 & 0.318 & 0.245 & 0.247 \\
\hline & & deepest & 0.969 & 0.991 & 0.864 & 0.841 \\
\hline & \multirow{2}{*}{0.8} & surface & 0.478 & 0.497 & 0.358 & 0.379 \\
\hline & & deepest & 1.132 & 1.156 & 0.997 & 1.008 \\
\hline
\end{tabular}

Table 5: Comparison between the SIFs calculated by the WF and FEM for the parabolic and cubic loading at ratio $R_{0} / R_{i}=1.5$. 


\begin{tabular}{|c|c|c|c|c|c|c|}
\hline \multirow{3}{*}{$a / c$} & \multirow{3}{*}{$\mathrm{c} / \mathrm{B}$} & \multirow{3}{*}{ Location } & \multicolumn{4}{|c|}{$K_{N}=K_{I} /\left(\sigma_{0} \cdot \sqrt{\pi a / Q}\right)$} \\
\hline & & & \multicolumn{2}{|c|}{ parabolic } & \multicolumn{2}{|c|}{ cubic } \\
\hline & & & WF & FEM & WF & FEM \\
\hline \multirow{8}{*}{0.2} & \multirow{2}{*}{0.2} & surface & 0.197 & 0.190 & 0.137 & 0.133 \\
\hline & & deepest & 0.452 & 0.459 & 0.419 & 0.417 \\
\hline & \multirow{2}{*}{0.4} & surface & 0.190 & 0.192 & 0.132 & 0.134 \\
\hline & & deepest & 0.449 & 0.449 & 0.415 & 0.414 \\
\hline & \multirow{2}{*}{0.6} & surface & 0.189 & 0.195 & 0.131 & 0.135 \\
\hline & & deepest & 0.442 & 0.450 & 0.407 & 0.420 \\
\hline & \multirow{2}{*}{0.8} & surface & 0.193 & 0.200 & 0.135 & 0.142 \\
\hline & & deepest & 0.435 & 0.456 & 0.401 & 0.421 \\
\hline \multirow{8}{*}{1} & \multirow{2}{*}{0.2} & surface & 0.169 & 0.177 & 0.111 & 0.117 \\
\hline & & deepest & 0.834 & 0.822 & 0.757 & 0.739 \\
\hline & \multirow{2}{*}{0.4} & surface & 0.199 & 0.205 & 0.134 & 0.138 \\
\hline & & deepest & 0.812 & 0.858 & 0.733 & 0.768 \\
\hline & \multirow{2}{*}{0.6} & surface & 0.270 & 0.276 & 0.190 & 0.196 \\
\hline & & deepest & 0.859 & 0.863 & 0.769 & 0.775 \\
\hline & \multirow{2}{*}{0.8} & surface & 0.382 & 0.374 & 0.279 & 0.275 \\
\hline & & deepest & 0.978 & 0.975 & 0.869 & 0.867 \\
\hline
\end{tabular}

Table 6: Comparison between the SIFs calculated by the WF and FEM for the parabolic and cubic loading at ratio $\mathrm{R}_{0} / \mathrm{R}_{\mathrm{i}}=2.25$.

\begin{tabular}{|c|c|c|c|c|c|c|}
\hline \multirow{3}{*}{$a / c$} & \multirow{3}{*}{$\mathrm{c} / \mathrm{B}$} & \multirow{3}{*}{ Location } & \multicolumn{4}{|c|}{$K_{N}=K_{I} /\left(\sigma_{0} \cdot \sqrt{\pi a / Q}\right)$} \\
\hline & & & \multicolumn{2}{|c|}{ parabolic } & \multicolumn{2}{|c|}{ cubic } \\
\hline & & & WF & FEM & WF & FEM \\
\hline \multirow{8}{*}{0.2} & \multirow{2}{*}{0.2} & surface & 0.197 & 0.204 & 0.138 & 0.141 \\
\hline & & deepest & 0.447 & 0.450 & 0.416 & 0.413 \\
\hline & \multirow{2}{*}{0.4} & surface & 0.192 & 0.194 & 0.133 & 0.137 \\
\hline & & deepest & 0.456 & 0.428 & 0.417 & 0.390 \\
\hline & \multirow{2}{*}{0.6} & surface & 0.193 & 0.194 & 0.135 & 0.137 \\
\hline & & deepest & 0.455 & 0.426 & 0.420 & 0.395 \\
\hline & \multirow{2}{*}{0.8} & surface & 0.192 & 0.197 & 0.137 & 0.139 \\
\hline & & deepest & 0.445 & 0.453 & 0.413 & 0.418 \\
\hline \multirow{8}{*}{1} & \multirow{2}{*}{0.2} & surface & 0.185 & 0.181 & 0.124 & 0.125 \\
\hline & & deepest & 0.868 & 0.823 & 0.788 & 0.748 \\
\hline & \multirow{2}{*}{0.4} & surface & 0.202 & 0.208 & 0.137 & 0.142 \\
\hline & & deepest & 0.810 & 0.819 & 0.729 & 0.724 \\
\hline & \multirow{2}{*}{0.6} & surface & 0.244 & 0.255 & 0.170 & 0.176 \\
\hline & & deepest & 0.827 & 0.831 & 0.740 & 0.735 \\
\hline & \multirow{2}{*}{0.8} & surface & 0.310 & 0.314 & 0.227 & 0.229 \\
\hline & & deepest & 0.916 & 0.936 & 0.818 & 0.828 \\
\hline
\end{tabular}

Table 7: Comparison between the SIFs calculated by the WF and FEM for the parabolic and cubic loading at ratio $\mathrm{R}_{0} / \mathrm{R}_{\mathrm{i}}=3.0$. 
Verification of the weight function

The dimensionless SIF results extracted from the present study under real pin loading by using both the WF and FE analysis are compared with those of Ref. [28] in Fig. 4 for $R_{\circ} / R_{i}=2, a / c=1$ and $0.2 \leq c / B \leq 0.8$. Kc and Ka represent the SIFs in the deepest and the surface points of the crack, respectively. The pin loading is modeled as a contact problem with zero friction. The SIFs obtained from the WF method, FEA and analytical results of Ref. [28] are approximately the same and are also given in Fig. 4 for comparison purpose.

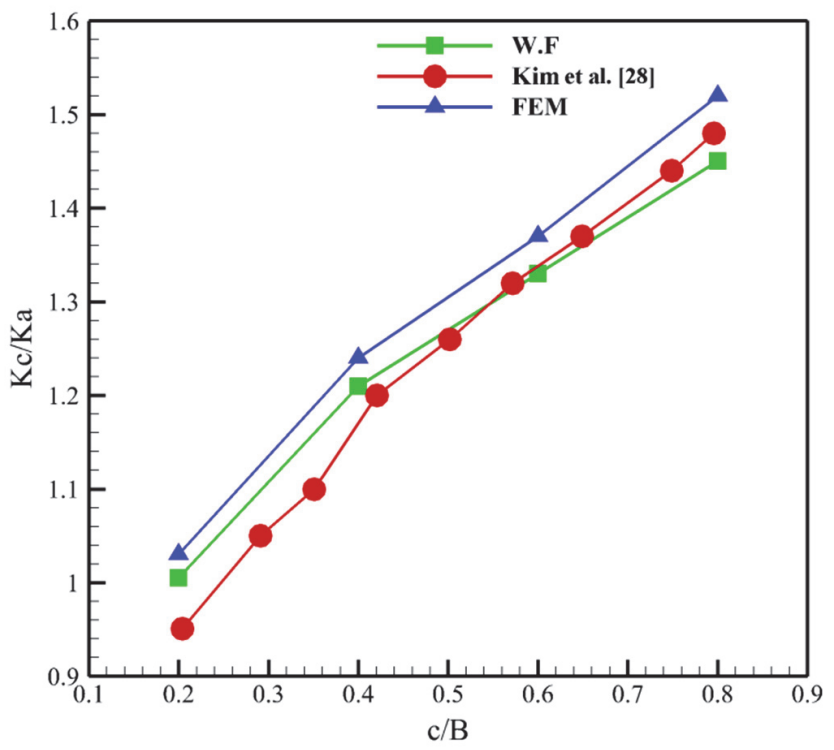

Figure 4: Dimensionless SIFs under the real pin loading at point $A$ and $C\left(R_{o} / R_{i}=2\right)$.

In addition, dimensionless SIFs $\left(\mathrm{K}_{\mathrm{N}}=\mathrm{K}_{\mathrm{I}} /\left(\sigma_{\mathrm{br}} \sqrt{ }{ }_{\pi} a\right)\right)$ under a real pin loading with frictionless contact are compared with those of Ref. [6] for $R_{o} / R_{i}=2.25, a / c=1$ and $0.2 \leq c / B \leq 0.8$ for the surface and the deepest points of the crack, listed in Tab. 8 and Tab. 9. The maximum difference of the SIFs obtained from WF and the analytical results of Ref. [6] is less than $8 \%$.

\begin{tabular}{cccc}
\hline & & $K_{N}=K_{I} /\left(\sigma_{b r} \cdot \sqrt{\pi a}\right)$ & \\
$\mathrm{c} / \mathrm{B}$ & FEM (present work) & WF (present work) & Analytical [6] \\
0.2 & 1.27 & 1.29 & 1.38 \\
0.4 & 1.04 & 1.09 & 1.07 \\
0.6 & 0.96 & 0.98 & 0.93 \\
0.8 & 0.89 & 0.93 & 0.86 \\
\hline
\end{tabular}

Table 8: SIFs of the surface point of the crack under real pin loading with contact $\mathrm{R}_{0} / \mathrm{R}_{\mathrm{i}}=2.25$.

\begin{tabular}{cccc}
\hline c/B & \multicolumn{3}{c}{$K_{N}=K_{I} /\left(\sigma_{b r} \cdot \sqrt{\pi a}\right)$} \\
\\
0.2 & FEM (present work) & WF (present work) & Analytical [6] \\
0.4 & 1.43 & 1.41 & 1.51 \\
0.6 & 1.38 & 1.35 & 1.41 \\
0.8 & 1.31 & 1.29 & 1.38 \\
\hline
\end{tabular}

Table 9: SIFs of deepest point of the crack under real pin loading with contact at $\mathrm{R}_{0} / \mathrm{Ri}=2.25$.

A comparison is done between the results of the WF and those in Ref. [14] for a lug with a quarter-circular crack subjected to a constant gross stress. The values of $a / \mathrm{c}$ and $R_{\mathrm{o}} / R_{\mathrm{i}}$ are 1 and 2.7, respectively. The results are compared in Tab. 10. 


\begin{tabular}{|c|c|c|c|c|}
\hline \multirow{3}{*}{$\mathrm{c} / \mathrm{B}$} & \multicolumn{4}{|c|}{$K_{N}=K_{I} /\left(\sigma_{b r} \cdot \sqrt{\pi a}\right)$} \\
\hline & \multicolumn{2}{|c|}{ Surface point } & \multicolumn{2}{|c|}{ Deepest point } \\
\hline & $\begin{array}{l}\text { WF (present } \\
\text { work) }\end{array}$ & WF[14] & WF (present work) & WF [14] \\
\hline 0.2 & 0.993 & 0.951 & 1.24 & 1.18 \\
\hline 0.4 & 0.805 & 0.788 & 1.18 & 1.15 \\
\hline 0.6 & 0.702 & 0.675 & 1.15 & 1.06 \\
\hline 0.8 & 0.636 & 0.617 & 1.13 & 1.06 \\
\hline
\end{tabular}

Table 10: SIFs of the surface point of the quarter-circular crack under real pin loading with contact $\mathrm{R}_{0} / \mathrm{R}_{\mathrm{i}}=2.7$.

Other approaches for simulating the pin loading are constant pressure and cosine pressure in the lug hole in the direction of pin load, which are also modeled in this work. The resulted SIFs are calculated using the WF according to Rigby and Aliabadi's work [12]. The presented cosine pressure loading in this study is defined as

$$
\sigma_{c}=\sigma_{0} \cos \theta
$$

where

$$
\sigma_{0}=2 P /\left(\pi R_{i} B\right)
$$

in which $P$ is resultant load in the y-direction and $\theta$ is the angle from pin loading direction according to coordinate system in Fig.1. A comparison between the present WF results and those in Ref. [12] is made in Tab. 11 and 12. The results are dimensionless according to Ref. [12]. The comparison of the results shows that the maximum difference between calculated

\begin{tabular}{|c|c|c|c|c|c|}
\hline \multirow[t]{3}{*}{$\mathrm{R}_{\mathrm{o}} / \mathrm{R}_{\mathrm{i}}$} & \multirow[t]{3}{*}{ Location } & \multicolumn{4}{|c|}{$K_{N}=K_{I} /\left(\sigma_{b r} \cdot \sqrt{\pi a}\right)$} \\
\hline & & \multicolumn{2}{|c|}{ cosine pressure } & \multicolumn{2}{|c|}{ uniform pressure } \\
\hline & & WF & BEM [12] & WF & BEM [12] \\
\hline \multirow[t]{2}{*}{1.5} & surface & 4.16 & 4.29 & 3.05 & 3.13 \\
\hline & deepest & 2.49 & 2.61 & 2.21 & 2.36 \\
\hline \multirow[t]{2}{*}{2.25} & surface & 1.58 & 1.66 & 1.19 & 1.23 \\
\hline & deepest & 1.17 & 1.21 & 0.91 & 0.99 \\
\hline \multirow[t]{2}{*}{3} & surface & 1.09 & 1.15 & 0.83 & 0.87 \\
\hline & deepest & 0.79 & 0.84 & 0.67 & 0.71 \\
\hline
\end{tabular}
SIFs using the present WF with those computed using BEM in Ref. [12] is about 7 percent.

Table 11: Comparison between the resulted SIFs of cosine pressure loading and uniform pressure loading for present WF and BEM of

\begin{tabular}{|c|c|c|c|c|c|}
\hline \multirow[t]{3}{*}{$\mathrm{R}_{\mathrm{o}} / \mathrm{R}_{\mathrm{i}}$} & \multirow[t]{3}{*}{ Location } & \multicolumn{4}{|c|}{$K_{N}=K_{I} /\left(\sigma_{\mathrm{br}} \cdot \sqrt{\pi \mathrm{a}}\right)$} \\
\hline & & \multicolumn{2}{|c|}{ cosine pressure } & \multicolumn{2}{|c|}{ uniform pressure } \\
\hline & & WF & BEM [12] & WF & BEM [12] \\
\hline \multirow[t]{2}{*}{1.5} & surface & 4.15 & 4.21 & 1.17 & 1.23 \\
\hline & deepest & 3.23 & 3.37 & 1.16 & 1.21 \\
\hline \multirow[t]{2}{*}{2.25} & surface & 1.59 & 1.68 & 0.83 & 0.87 \\
\hline & deepest & 1.45 & 1.51 & 0.83 & 0.87 \\
\hline \multirow[t]{2}{*}{3} & surface & 1.12 & 1.17 & 1.18 & 1.23 \\
\hline & deepest & 0.99 & 1.06 & 1.13 & 1.21 \\
\hline
\end{tabular}
Ref.[12] for $a / \mathrm{c}=1$ and $\mathrm{c} / \mathrm{B}=0.5$.

Table 12: Comparison between the resulted SIFs of cosine pressure loading and uniform pressure loading for present the WF and BEM of Ref.[12] for $a / c=0.66$ and $c / B=0.5$. 


\section{EVALUATING THE EFFECT OF PIN LOADING CONDITIONS AND CRACK PARAMETERS VARIATION}

$\mathrm{I}$

$\mathrm{n}$ order to model pin loading in the attachment lug, three methods could be implemented. These three methods are the real pin loading (contact between pin and lug hole), the constant pressure and the cosine pressure. Here a study is done to evaluate the effect of each loading conditions on the resulted SIFs. The results are calculated for $R_{\circ} / R_{\mathrm{i}}=2$, $a / \mathrm{c}=1,0.2 \leq \mathrm{c} / \mathrm{B} \leq 0.8,9.6 \mathrm{kPa}$ gross stress, which are presented in Tabs. 13 and 14 . It is evident that the real pin loading has the largest values for SIFs than the other two methods. Among the three common types of loading in the lug hole, the real pin loading condition has the largest magnitude of the SIFs. Further, it is obvious that when c/B increases, values of SIFs increase in both deepest and surface points of the crack because of the effect of crack depth on the SIF.

\begin{tabular}{cccc}
\hline$c / B$ & Real pin loading & Constant pressure & Cosine pressure \\
0.2 & 0.0615 & 0.0603 & 0.0591 \\
0.4 & 0.0718 & 0.0683 & 0.0677 \\
0.6 & 0.0926 & 0.0902 & 0.0891 \\
0.8 & 0.1178 & 0.1143 & 0.1121 \\
\hline
\end{tabular}

Table 13: SIFs $\left(\mathrm{MPa}(\mathrm{mm})^{0.5}\right)$ for surface point of the crack under three types of pin loading for $\mathrm{R}_{0} / \mathrm{R}_{\mathrm{i}}=2$ and $a / \mathrm{c}=1$.

\begin{tabular}{cccc}
\hline$c / B$ & Real pin loading & Constant pressure & Cosine pressure \\
0.2 & 0.0708 & 0.069 & 0.061 \\
0.4 & 0.101 & 0.098 & 0.092 \\
0.6 & 0.129 & 0.121 & 0.117 \\
0.8 & 0.1562 & 0.1518 & 0.148 \\
\hline
\end{tabular}

Table 14: SIFs $\left(\mathrm{MPa}(\mathrm{mm})^{0.5}\right)$ for deepest point of the crack under three types of pin loading for $\mathrm{R}_{0} / \mathrm{R}_{\mathrm{i}}=2$ and $a / \mathrm{c}=1$.

In order to study the effect of $a / \mathrm{c}$ and $\mathrm{c} / \mathrm{B}$ on the SIFs, a comparison is done for different values of $a / \mathrm{c}$ and $\mathrm{c} / \mathrm{B}$ using the WF method. The results are shown in Fig. 5 and Fig. 6 for the real pin loading model. It could be concluded that by changing the shape of the crack from a quarter circle to a quarter ellipse, the values of the SIFs for surface points of the crack increase despite the fact that the SIF values for deepest points of the crack decrease. Also for both points when $a / \mathrm{c}<1$, by increasing the $a / \mathrm{c}$, SIF values increase. It is obvious that increasing the $\mathrm{c} / \mathrm{B}$ would increase the value of SIFs in surface and deepest points.

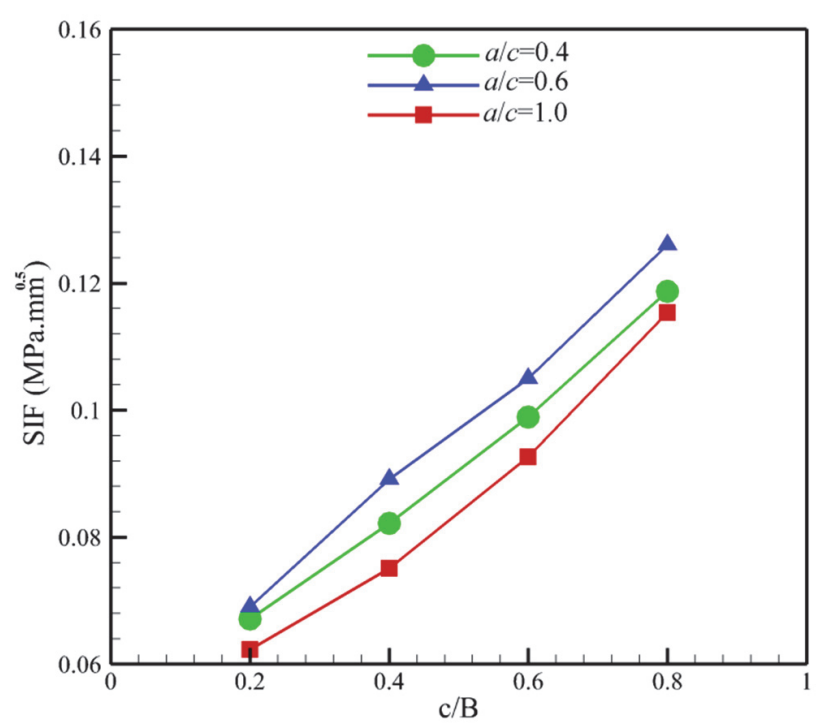

Figure 5: Variation of SIFs vs. c/B for the surface point of the crack under the real pin loading for different a/c ratios. 


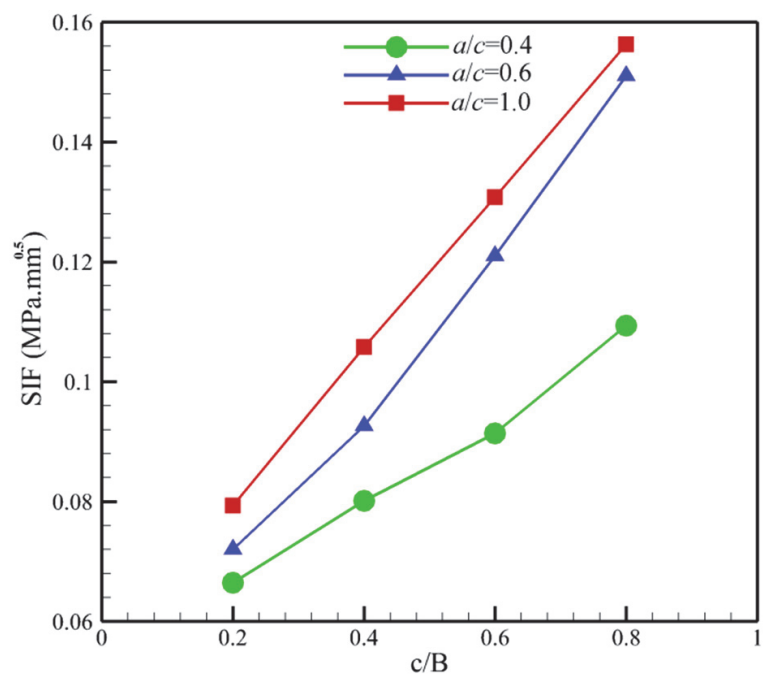

Figure 6: Variation of SIFs vs. c/B for the deepest point of the crack under the real pin loading for different a/c ratios.

\section{EVALUATING THE EFFECT OF BUSH AND INTERFERENCE FITTING}

$\mathrm{O}$

ne of the cases for the contact between the lug and the pin is when the diameter of the pin is a little larger than the lug hole, which is called interference loading. Another approach is when a bush exists between the pin and lug hole (in this case the bush would have interference contact with the hole of lug) and the contact between the pin and the bush is neat. In this paper the amount of interferences for both cases is considered $0.1 \mathrm{~mm}$ and the consequence effects are studied for different values of $a / \mathrm{c}, \mathrm{c} / \mathrm{B}$ and fixed value of $\mathrm{R}_{o} / \mathrm{R}_{i}=2.25$. The thickness of bush is $1 \mathrm{~mm}$ and it is made of the same material as the lug. The analysis was performed for $100 \mathrm{kN}$ force of pin. The results are compared with the those obtained from neat loading condition without any interferences and bush in Tab. 15. It is obvious that the values of SIFs for neat contact between the pin and the lug are more than the case of interference contact and the bush existence. That is the reason why these two cases are used in fatigue conditions for increasing the life time. By comparing the results between the interference contact of the pin and the lug and the case that the bush exists, it can be understood that in the presence of bush, the values of SIFs are lower than the other. This is a study for this case of loading and for choosing an appropriate value for the interference to have a benefit effect on the fatigue life of the lug, the extracted WF could be used to avoid the time consumer modelling and analysing.

\begin{tabular}{|c|c|c|c|c|c|}
\hline \multirow{2}{*}{$a / c$} & \multirow{2}{*}{$\mathrm{c} / \mathrm{B}$} & \multirow{2}{*}{$\begin{array}{l}\text { Point } \\
\text { location }\end{array}$} & \multicolumn{3}{|c|}{$\mathrm{K}_{\mathrm{I}}(M P a \sqrt{m m})$} \\
\hline & & & Neat loading & Interference & With bush \\
\hline \multirow{8}{*}{0.2} & \multirow{2}{*}{0.2} & surface & 426.972 & 378.88 & 370.98 \\
\hline & & deepest & 218.556 & 192.959 & 188.99 \\
\hline & \multirow{2}{*}{0.4} & surface & 576.559 & 517.312 & 506.279 \\
\hline & & deepest & 323.459 & 287.412 & 277.315 \\
\hline & \multirow{2}{*}{0.6} & surface & 693.524 & 628.975 & 615.364 \\
\hline & & deepest & 412.142 & 364.62 & 351.471 \\
\hline & \multirow{2}{*}{0.8} & surface & 794.21 & 728.448 & 712.531 \\
\hline & & deepest & 487.162 & 432.112 & 417.291 \\
\hline \multirow{8}{*}{1} & \multirow{2}{*}{0.2} & surface & 654.173 & 610.42 & 607.183 \\
\hline & & deepest & 718.31 & 638.72 & 625.38 \\
\hline & \multirow{2}{*}{0.4} & surface & 854.616 & 826.41 & 824.37 \\
\hline & & deepest & 1012.92 & 914.711 & 895.211 \\
\hline & \multirow{2}{*}{0.6} & surface & 1030.5 & 1008.37 & 987.51 \\
\hline & & deepest & 1283.41 & 1173.69 & 1148.81 \\
\hline & \multirow{2}{*}{0.8} & surface & 1248.31 & 1121.21 & 1106.14 \\
\hline & & deepest & 1591.54 & 1196.32 & 1138.26 \\
\hline
\end{tabular}

Table 15: SIFs $\left(\mathrm{MPa}(\mathrm{mm})^{0.5}\right)$ for crack under the pin loading in three conditions. 


\section{CONCLUSION}

$\mathrm{I}$ $\mathrm{n}$ the present work, a WF has been proposed to predict the stress intensity factor for cracked lugs with various geometrical parameters. A quarter-elliptical crack was considered at the inner surface of the attachment lug. For this aim a series of 3D FE analyses have been done for two reference loadings (uniform and linear). Lug parameters and their ranges which have been considered as variants in these analyses were $1.5 \leq \mathrm{R}_{\circ} / \mathrm{R}_{\mathrm{i}} \leq 3,0.2 \leq a / \mathrm{c} \leq 1$ and $0.2 \leq \mathrm{c} / \mathrm{B} \leq 0.8$. The achieved WF has been considered a function of these three parameters, which gives this ability to predict the SIFs in lugs with different loading condition, geometries and crack configurations. This characteristic helps to study this wide range of lug family, without any need to other time consumer approach and beside that, the accuracy of this method is confirmed. It has been validated by comparing the calculated SIFs of WF and those reported in the literatures. It was evident that the results had good agreement with considering the average of the differences. In addition, the effects of three approaches of pin loading model on the SIFs values have been studied using the extracted weight function. These three types of the pin loading have been modeled as the real pin loading with contact to the lug hole, the constant pressure and the cosine pressure on the lug hole. The results have shown that the real pin loading gives the largest values of SIFs and it is the accurate approach in life estimation. In the next part of the paper, the effects of the variation of crack parameters $(a / \mathrm{c}$ and $\mathrm{c} / \mathrm{B})$ on SIF values have been studied.

At the end of this paper in order to study the effect of the interference between the pin and the lug contact and also the effect of bush existence on the SIFs variation, the extracted weight function in present study has been applied. It have been observed that the values of SIFs for neat contact between the pin and the lug are more than the case in the presence of interference and bush with interference in contact condition. For the considered loading it is obvious that the use of interference in lug and pin contact and also the use of bush with interference between them can improve the fatigue life of the lug. It should be noted that the value of interference should be calculated in order to have a beneficial effect on the life of the lug. Therefore the extracted weight function could be used without any extra modelling and time consuming analysis for different cases.

\section{REFERENCES}

[1] Jiang, Y., She, C., Yu, P. and Guo, W. (2011). Three-dimensional stress concentrations at circular pin holes in clearancefit lugs. Fatigue Fract Eng Mater Struct, 34(8), pp. 573-580. DOI: 10.1111/j.1460-2695.2011.01548.x.

[2] Wang, G. S. (1994). Stress analysis for a lug under various conditions. J. Strain Anal Eng, 29(1), pp. 7-16. DOI: $10.1243 / 03093247 \mathrm{v} 291007$.

[3] Grant, R. J. and Flipo, B. C. D. (2009). Parametric study of the elastic stress distribution in pin-loaded lugs modelled in two and three dimensions and loaded in tension. J. Strain Anal Eng, 44(6), pp. 473-489. DOI: 10.1243/03093247jsa501.

[4] Kathiresan, K., Hsu, T. M. and Rudd, J. L. (1984). Stress and Fracture Analysis of Tapered Attachment Lugs. Fracture Mechanics: Fifteenth Symposium. ASTM STP 833, R. J. Sanford, Ed., American Society for Testing and Materials, Philadelphia.

[5] Hsu, T. M. (1981). Analysis of Cracks at Attachment Lugs. J. Aircraft, 18(9), pp. 755-760. DOI: 10.2514/3.57558.

[6] Kathiresan, K., Brussat, T. R. and Rudd, J. L. (1985). Crack growth analyses and correlations for attachment lugs, J. Aircraft, 22(9), pp. 818-824. DOI: 10.2514/3.45207.

[7] Narayana, K. B., Dayananda, T. S., Dattaguru, B., Ramamurthy, T. S. and Vijayakumar, K. (1994). Cracks emanating from pin-loaded lugs. Eng Fract Mech, 47(1), pp. 29-38. DOI: 10.1016/0013-7944(94)90235-6,

[8] Boljanović, S. and Maksimović, S. (2016). Fatigue failure analysis of pin-loaded lugs. Frattura ed Integrità Strutturale, 35, pp. 313-321. DOI: 0.3221/IGF-ESIS.35.36

[9] Boljanović, S., Maksimović, S. and Djurić, M. (2016). Fatigue strength assessment of initial semi-elliptical cracks located at a hole. Int J Fatigue, 92, Part 2, pp. 548-556. DOI: 10.1016/j.ijfatigue.2016.04.011.

[10] Naderi, M. and Iyyer, N. (2015). Fatigue life prediction of cracked attachment lugs using XFEM. Int J. Fatigue, 77, pp. 186-193. DOI: 10.1016/j.ijfatigue.2015.02.021.

[11] Naderi, M., Sarkar, S., Amiri, M. \& Iyyer, N. (2016). Extended isogeometric analysis (XIGA) of fatigue life in attachment lug. J Fail Anal Prev, 16(4), pp. 601-611. DOI: 10.1007/s11668-016-0125-y

[12] Rigby, R. and Aliabadi, M. H. (1997). Stress intensity factors for cracks at attachment lugs. Eng Fail Anal, 4(2), pp. 133146. DOI: $10.1016 / \mathrm{S} 1350-6307(97) 00004-6$. 
[13] Wang, G. S. (1992). Weight functions and stress intensity factors for the single crack round-ended straight lug. Int J Fract, 56(3), pp. 233-255. DOI: 10.1007/BF00012329.

[14] Mikheevskiy, S., Glinka, G. and Algera, D. (2012). Analysis of fatigue crack growth in an attachment lug based on the weight function technique and the UniGrow fatigue crack growth model. Int J Fatigue, 42, pp. 88-94. DOI: 10.1016/j.ijfatigue.2011.07.006.

[15] Wu, X. R. \& Tong, D. H. (2018). Evaluation of various analytical weight function methods base on exact K-solutions of an edge-cracked circular disc. Eng Fract Mech, 189, pp.64-80. DOI: 10.1016/j.engfracmech.2017.09.024.

[16] Xu, W., Wu, X. R., Yu, Y. and Li, Z. H. (2018). A weight function method for mixed modes hole-edge cracks. Fatigue Fract Eng Mater Struct, 41, pp. 223-234. DOI: 10.1111/ffe.12674.

[17] Bahloul, A., BenAhmed, A. and Bouraoui, C. (2018). An engineering predictive approach of fatigue crack growth behavior: The case of the lug-type joint. Comptes Rendus Mécanique, 346(1), pp. 1-12. DOI: 10.1016/j.crme.2017.10.003.

[18] Fawaz, S. A., Andersson, B. and Newman Jr, J. C. (2003). Experimental. Verification of Stress Intensity Factor Solutions for Corner Cracks at a Hole. Subject to General Loading. ICAF, Fatigue of aeronautical structures as an engineering challenge.

[19] Newman, J. C., Jr and Raju, I. S. (1984). Stress-intensity factor equations for cracks in three-dimensional finite bodies subjected to tension and bending loads. NASA; United States.

[20] Chikmath, L. and Dattaguru, B., (2017). Prognostic analysis of fastener joints in straight attachment lugs. Int J Struct Inte, 8(3), pp. 404-422. DOI: 10.1108/IJSI-09-2016-0031

[21] ABAQUS. (2012). Dassault Systèmes Inc., USA.

[22] Pook, L. P. (1994). Some implications of corner point singularities. Eng Fract Mech, 48, pp. 367-378. DOI: 10.1016/0013-7944(94)90127-9

[23] Nabavi, S. M. and Shahani, A. R. (2014). Dynamic stress intensity factors for a longitudinal semi-elliptical crack in a thick-walled cylinder. Int J Eng Sci Technol, 6(5), pp. 57-77.

[24] Pook, L. P. (2000). Crack profiles and corner point singularities. Fatigue Fract Eng Mater Struct, 23(2), pp. 141-150. DOI: $10.1046 /$ j.1460-2695.2000.00249.x.

[25] Anderson, T.L. (2017). Fracture Mechanics: Fundamentals and Applications, 4th Edition, Boca Raton, CRC Press.

[26] Shen, G. and Glinka, G. (1991). Weight functions for a surface semi-elliptical crack in a finite thickness plate. Theor Appl Fract Mech, 15(3), pp. 247-255. DOI: 10.1016/0167-8442(91)90023-D.

[27] Fett, T., Mattheck, C. and Munz, D. (1987). On the calculation of crack opening displacement from the stress intensity factor. Eng Fract Mech, 27(6), pp. 697-715. DOI: 10.1016/0013-7944(87)90159-7.

[28] Kim, J.-H., Lee, S.-B. and Hong, S.-G. (2003). Fatigue crack growth behavior of Al7050-T7451 attachment lugs under flight spectrum variation. Theor Appl Fract Mech, 40(2), pp. 135-144. DOI: 10.1016/S0167-8442(03)00041-7. 